\title{
IST Exclusive - Interview on Paint Expo 2022
}

\author{
On December 1, 2020, Paint Expo was taken over by Leipziger Messe GmbH. This presented \\ Holger Seybold, editor-in-chief of IST, with the ideal opportunity to travel to Leipzig and meet with \\ Markus Geisenberger, CEO of Leipziger Messe, and Ivonne Simons, project director of Paint Expo, \\ for an exclusive interview about the future of the world's leading trade fair for industrial coating \\ technology.
}

Some background information before we begin: Paint Expo was first held in 2006 and quickly became the world's leading trade fair for industrial coating technology. Every two years, the who's who of the industry come together at the exhibition center in Karlsruhe (Germany). The number of exhibitors and visitors and the size of the exhibition area have been constantly growing over the years. As a result of the coronavirus pandemic, Paint Expo was postponed until the fall of 2020, but then had to be canceled completely. It was subsequently taken over by Leipziger Messe, which became the new organizer.

Leipziger Messe has many years' experience of organizing industry exhibitions. At the end of last year, you took over Paint Expo from Fair Fair $\mathrm{GmbH}$ and integrated it into your portfolio. Are you now starting from scratch? Will you be completely reinventing Paint Expo? Markus Geisenberger:

We have a long history of taking over trade fairs that have been held with great success. Our experience tells us that we need to make the most of all the good work that has already been done. We will make every effort to continue the success story by taking over the core elements of the concept and moving forward with them.

In the transition phase, we aim to learn a lot from everyone who worked on the exhibition in the past. Jürgen Haußmann, the former organizer of Paint Expo, is still on board in an advisory role. It is important for us to understand exactly what our customers, exhibitors and visitors want.

Paint Expo is the world's leading trade fair for industrial coating technology and has been extremely successful in the past. Our aim is to continue that success. We have extensive expertise in staging industry exhibitions and trade fairs and working with the automotive industry and its suppliers, which will be extremely useful to us.

Ivonne Simons:

We also have an advisory committee that has provided support for Paint Expo over

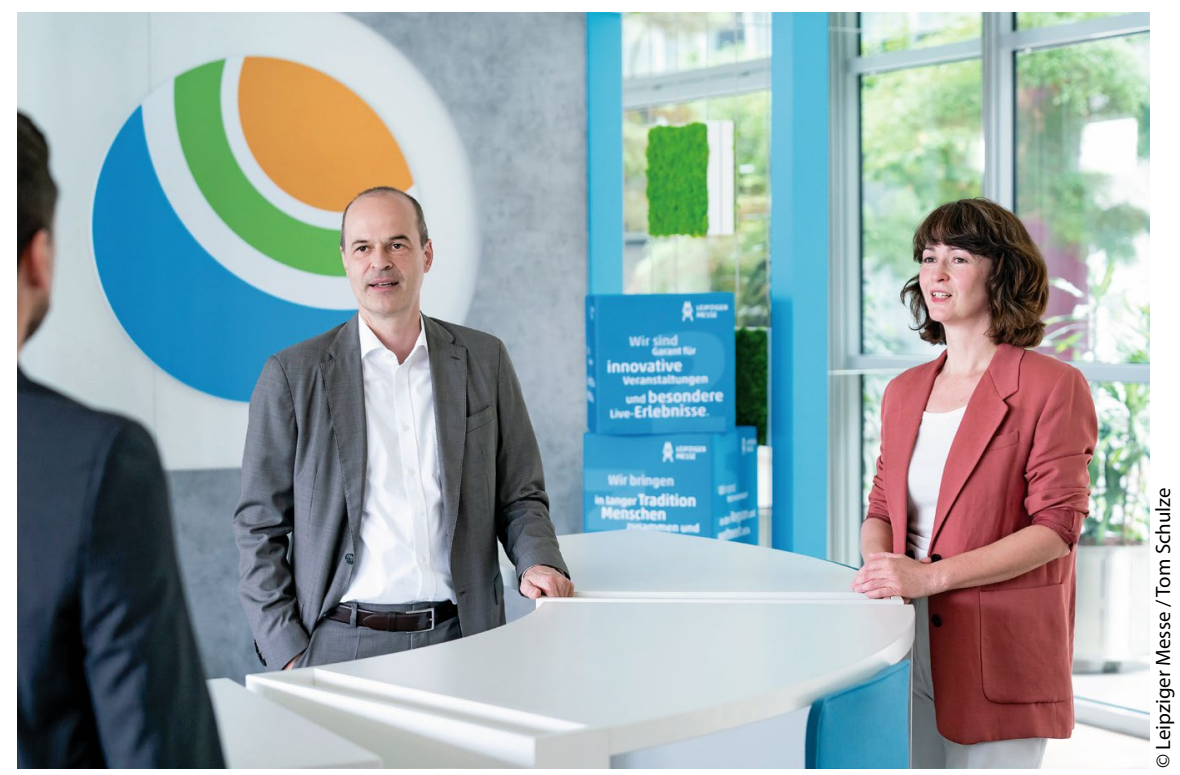

Markus Geisenberger (left), CEO of Leipziger Messe, und Ivonne Simons (right), project director of Paint Expo, during the exclusive IST interview. many years. The committee will act as a sounding board for us so that we can make sure that we are all moving in the right direction.

Markus Geisenberger:

The advisory committee will play an essential role for us. The members have different perspectives and can both speak and listen on our behalf. We are relying heavily on the committee, because it can channel the interests of exhibitors and partners. It sounds very trivial, but the key to a successful exhibition is always to listen very closely to the customers. 


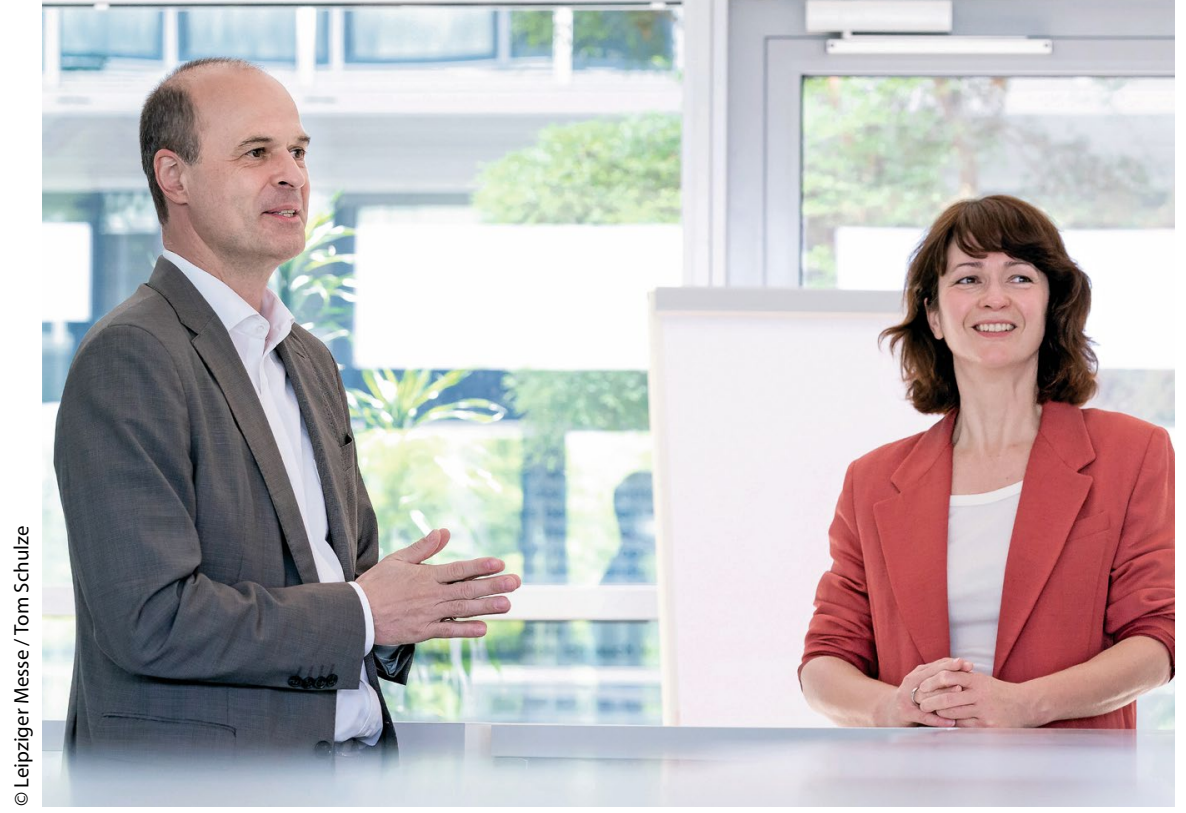

The goal of Leipziger Messe as the organizer is to make every effort to continue the Paint Expo success story.

Our job is to discover where the developments are going and, of course, we rely on the committee's expertise in this respect. When you take over a trade fair, you have a lot of your own knowledge to contribute. But you also need to be aware that there are other people who know much more about the subject than you do.

Here in Leipzig you have your own large exhibition center, but Paint Expo will take place in Karlsruhe next year. Is that just a transitional solution? Or will Karlsruhe definitely be the venue in the future?

Markus Geisenberger:

The organizer of the event is, of course, Leipziger Messe, but you need to understand that Leipziger Messe does 30 percent of its business at other locations both inside and outside Germany. We hold in- dustry exhibitions in Munich, Düsseldorf, Hamburg and Kassel, and now also in Karlsruhe. It is very important to us that there is continuity in terms of the venue so that we can take the existing success story forward.

We know the people at Messe Karlsruhe well, we value their expertise and the partnership that we have with them, which will now, of course, become much closer. We are confident that we can work together well. We plan to stay in Karlsruhe in the long term, because we believe it is an excellent location and is ideal for the ongoing development of Paint Expo.

We would like to make it quite clear that the industry exhibitions will take place wherever they are at home. We are the organizer and we go to these locations with our customers.

\section{Leipziger Messe}

Leipziger Messe is one of the ten leading trade fair companies in Germany and one of the top 50 worldwide. It holds events in Leipzig and at a variety of locations both inside and outside Germany. With its five subsidiaries and the Congress Center Leipzig (CCL), Leipziger Messe provides a comprehensive range of services covering the entire event organization sector. Every year, around 270 events take place - trade fairs, exhibitions and congresses - with over 15,500 exhibitors and more than 1.2 million visitors from all over the world. By taking a strategic approach to business development, which involves buying trade fairs, creating new exhibition formats and entering into new partnerships, Leipziger Messe is constantly expanding its portfolio.

The Leipziger Messe group in figures:

$\begin{array}{ll}\text { Total events: } & 280 \\ \text { Its own trade fairs: } & 32 \\ \text { Exhibitors: } & 15,360 \\ \text { Visitors: } & 1.2 \text { million } \\ \text { Offices abroad: } & 25\end{array}$

1) All the figures provided by the Leipziger Messe Group are from 2019, before the coronavirus pandemic.

Taking over an established trade fair, as is the case here, can involve some friction. And apart from that there is a lot of organizing to be done in advance. How are the preparations going? What is working well and where have you encountered difficulties?

Markus Geisenberger:

The big challenge we are facing in this case has less to do with the takeover and more to do with the unprecedented situation that forms the backdrop to it.

Paint Expo was last held in 2018. It was canceled in 2020 and after that we took over. Given all the problems caused by the coronavirus pandemic, we have not been able to follow the normal cycle of preparations. Unfortunately, we did not have the full two-year period to prepare for the event.

These are the biggest challenges that our team and also our customers and partners ultimately have to deal with, because everyone simply started later.

This means that we need to put a lot of effort and drive into getting everything done and ensuring that the exhibition is a success. Despite all of this, the preparations for Paint Expo in April 2022 are going very well and the event has been very well received.

Ivonne Simons:

I'm very pleased with the preparations and the current status of our plans. The first and most important step for us was to start bringing exhibitors on board in good time and in line with our schedule and we succeeded in doing this in the early part of the summer. We are very happy with the great response that we have received so far. We have had a lot of positive feedback. Of course, there are a lot of processes going on in the background that we have to manage. The workflows need to be integrated and we have to set up new interfaces, but our customers are not normally aware of any of this. It is in the nature of a takeover of this kind that there is always an enormous amount to do for the first event. But this investment will pay off later, because our goal is always to provide a better quality service for our customers. One example is our online booking system for exhibitors. Leipziger Messe aims to offer the full range of services so that our exhibitors' preparations for the trade fair are straightforward and simple. Fortunately, we've had a lot of support from our in-house colleagues who all enjoy tackling new projects. 


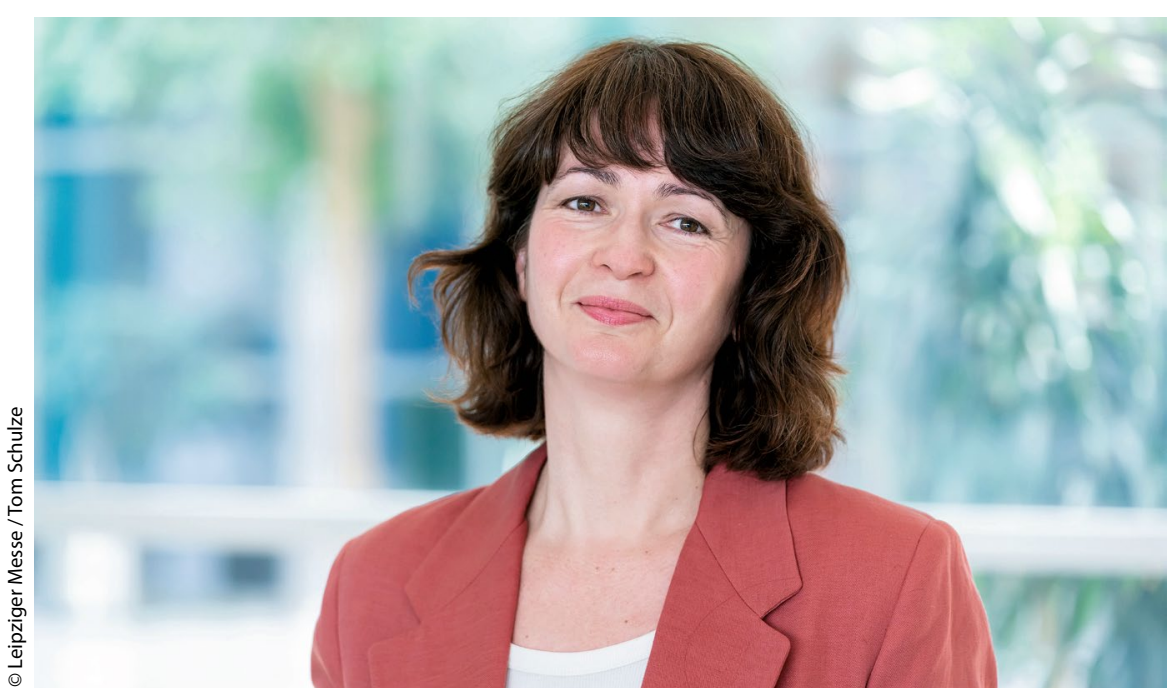

Ivonne Simons, project director at Paint Expo, is pleased about the excellent response and positive feedback from the industry.

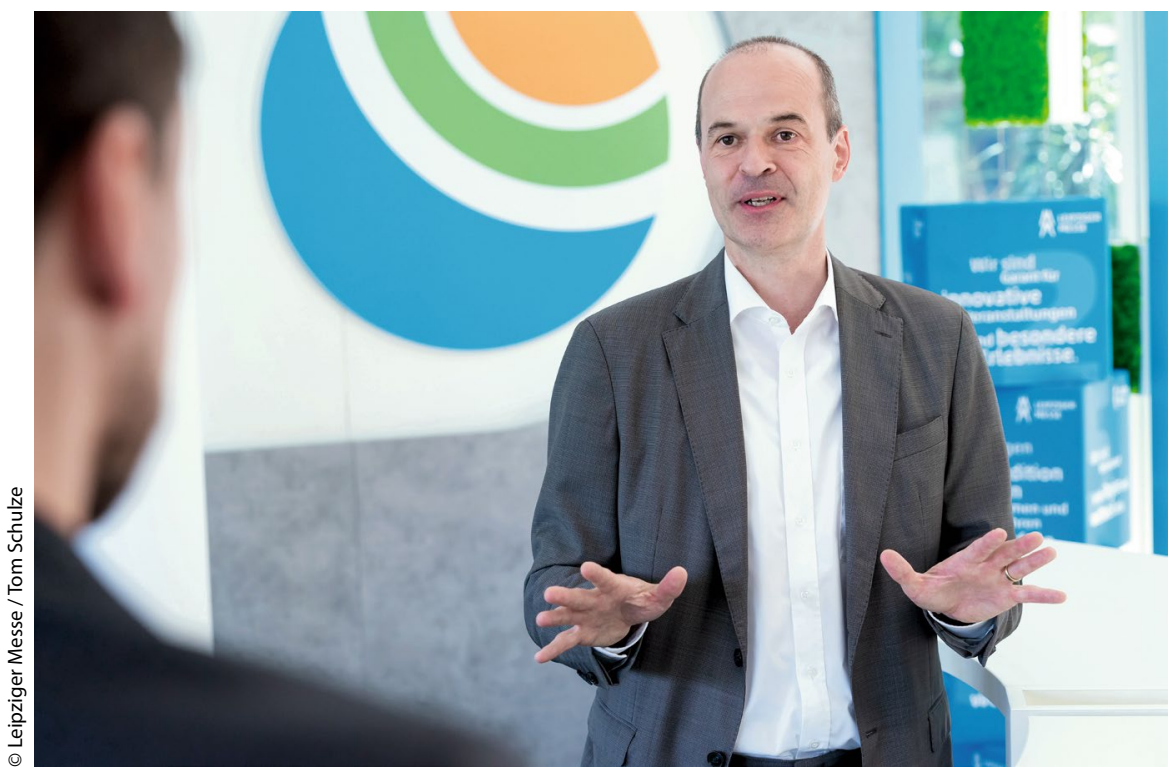

CEO Markus Geisenberger promises to continue to develop Paint Expo for the benefit of customers, exhibitors and visitors.

There are a few months until the event itself and the booking phase is still ongoing. Can you give us an idea of the level of bookings? Has the exhibition been well received by the industry?

Ivonne Simons:

We are really excited about how fast the bookings have been coming in. Currently, more than 360 exhibitors have already registered. And if you look at the range of companies, they cover all areas of the industry, which means that in April 2022 we will once again be the showcase for industrial coating technology. The entire bandwidth of products and services will be on display at the event, will once again be there. There are market leaders, global players and research institutions on the list. There is a wide variety of products and services and a lot for visitors to see.

Exhibitors still have until the end of November to register. The booking phase is by no means over and we are still working on the positioning and the coordination.

Markus Geisenberger:

Even in the registration phase, Paint Expo is living up to its reputation of being the world's leading trade fair for industrial coating technology and naturally we're very pleased about that.

As things currently stand, no one can reliably predict how the coronavirus pandemic is likely to progress. What measures have you taken or will you take to make sure that you can hold the event safely regardless of what happens? Ivonne Simons:

As far as the pandemic goes, we are working on the basis that the date in April 2022 is fixed. The entire exhibition industry is getting back to work and events are now being held again. We have made use of tried-and-tested hygiene solutions and gained experience in a variety of different settings. We will be working closely with Messe Karlsruhe to develop concepts for this event. It goes without saying that the health and safety of the participants is our top priority when it comes to making sure that the trade fair can go ahead as planned.

Markus Geisenberger:

At Leipziger Messe, we have already been able to demonstrate over the past year that we can hold events responsibly and safely during the pandemic and we have acquired some specific expertise in this area. Our "Safe Expo" hygiene concept, which we have developed during this challenging period, helps to ensure that our events are safe. Of course, we also need the right conditions to guarantee that we can go ahead regardless of the incidence rate.

The public debate is going in precisely this direction at the moment and that is

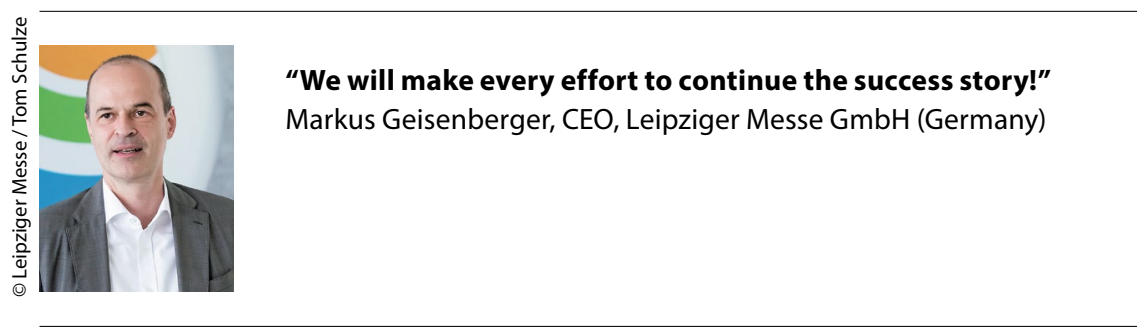




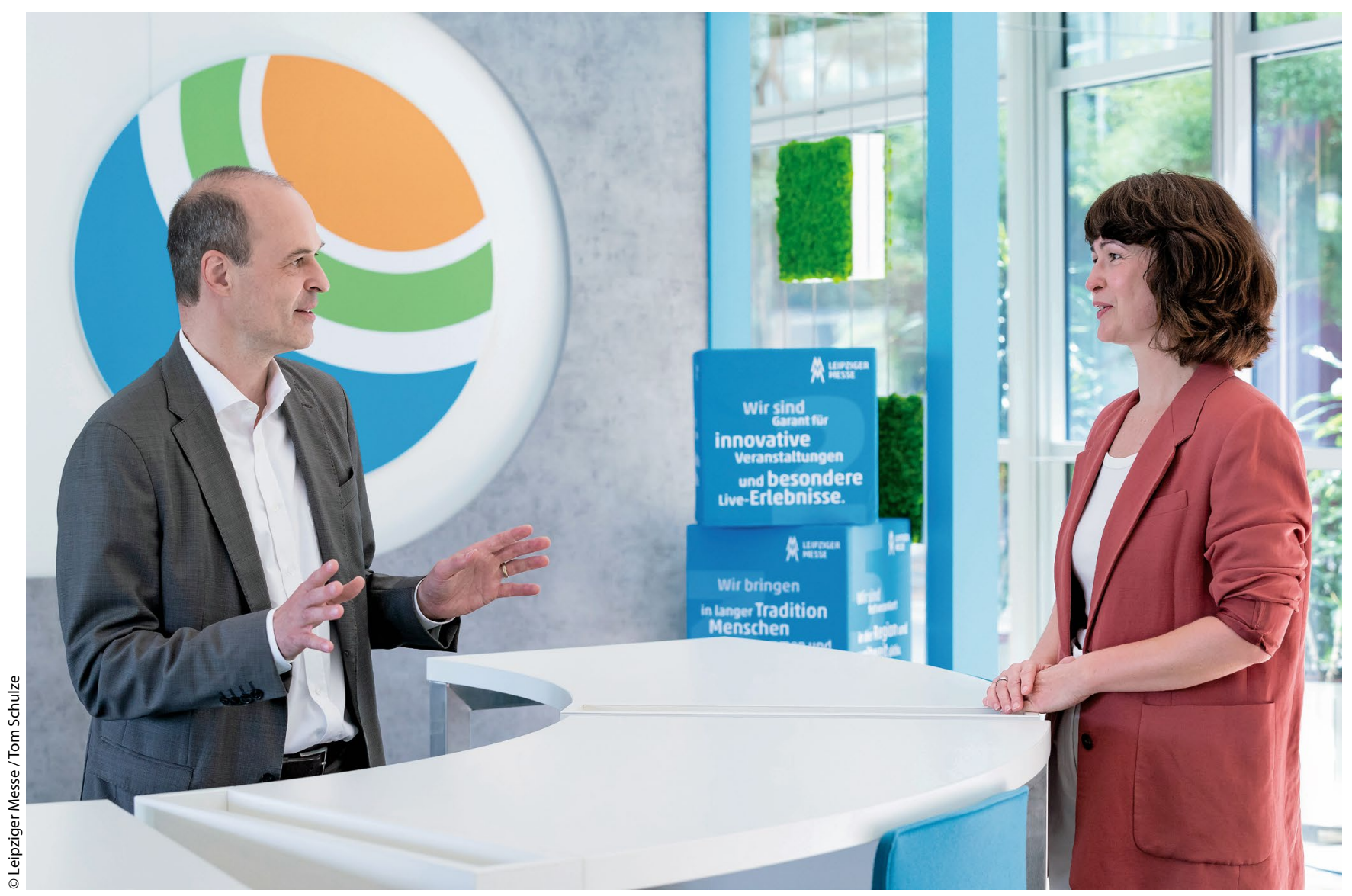

The organizers have several new online offerings in their repertoire that will complement the in-person event.

why we are very confident that we can go ahead with our preparations for April 2022, as we are currently doing.

\section{Will you be staging a traditional in-per- son event or are you planning a hybrid variant? Will there be additional online offerings?}

Ivonne Simons:

Our customers have made it quite clear to us that an in-person event is what is important to them. Making personal contacts is precisely what they have missed over the last two years. There is a mood of excitement and anticipation. This is why we are putting the emphasis on meeting face to face.

At the same time, we have worked hard over recent months on improving our digital skills. We have several new offerings in our repertoire that will complement the in-person event by helping with making contacts on site, networking and sharing experiences.

There will be some innovations, especially given that the last Paint Expo was held in 2018. A lot has happened since then.
As part of the relaunch of the website, we will definitely be introducing some new offerings over the next year to give exhibitors the chance to take advantage of a better online presence for their companies and their products. There will be a new exhibitor and product directory that will be connected to digital tools for matchmaking and appointments. This will allow for more efficient and more targeted visits to the exhibition so that networking is easier and better for everyone, especially as there are "only" four days to visit the trade fair.
To sum up, it's all about enabling all the participants to prepare for the exhibition more effectively and providing an online extension of the event.

\section{So the platform will make all the information available online after the in-person event has ended?}

Ivonne Simons:

Yes, exactly. We want to use the time between the trade fairs and make reference material available on the platform. This will allow people to get in touch outside

\section{Paint Expo 2022}

In 2018, Paint Expo had more than 500 exhibitors from around 30 countries and over 11,000 industry visitors from almost 90 countries. The world's leading trade fair for industrial coating technology is the showcase for innovations, applications, future technologies and trends in the field of painting. These are the details of next year's Paint Expo:

$\begin{array}{ll}\text { Dates: } & \text { April 26, 2022 - April 29, } 2022 \\ \text { Venue: } & \text { Messe Karlsruhe } \\ \text { Satnav: } & \text { Messeallee 1, 76287 Rheinstetten (Germany) } \\ \text { Opening hours: } & \text { 9:00- 17:00 (on April 29 until 16:00) } \\ \text { Web: } & \text { www.paintexpo.de }\end{array}$




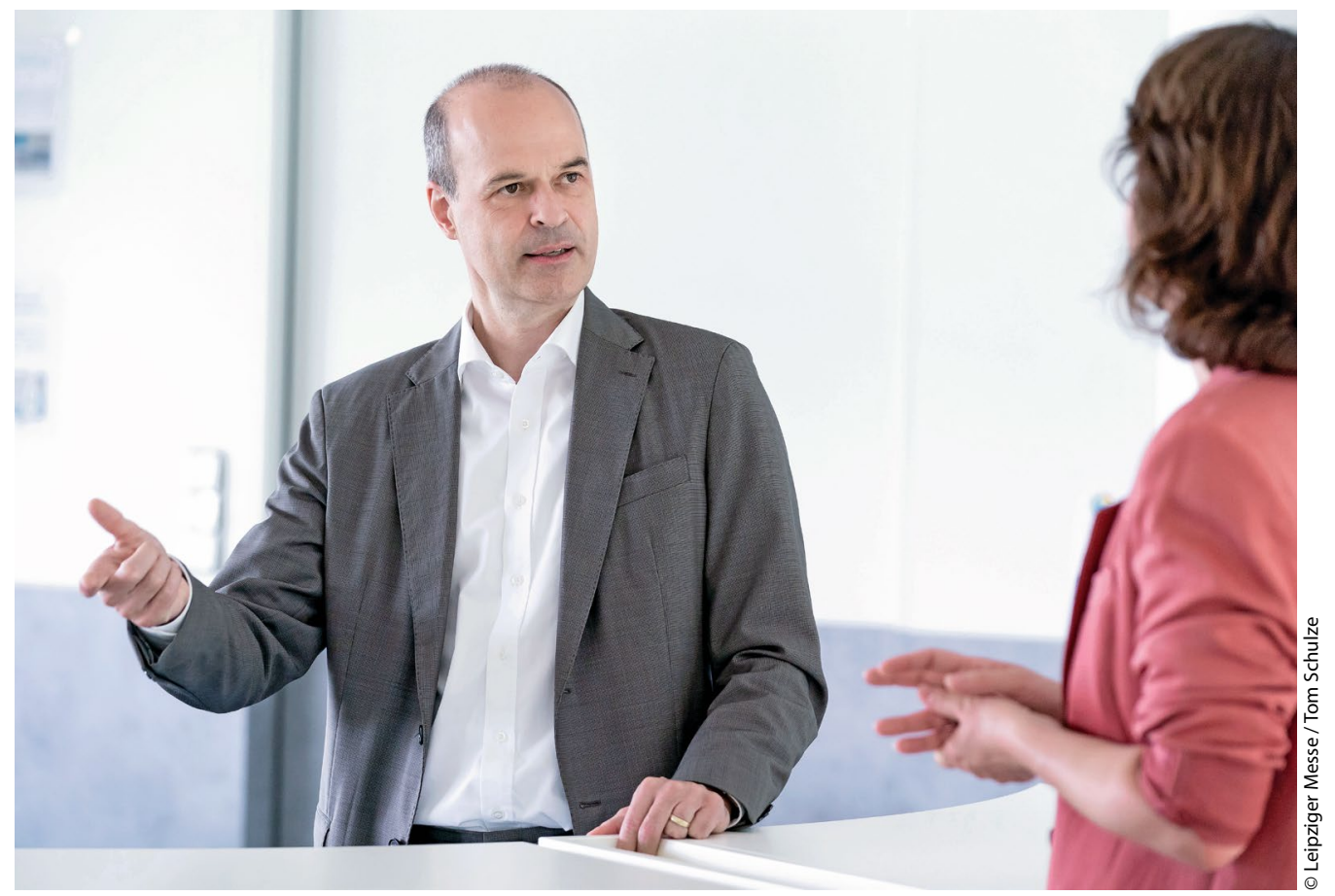

The registration lists indicate that the who's who of the industry will once again be present in Karlsruhe in April 2022.

the confines of the exhibition and to find out what is available on the market and who the main players and suppliers are.

This leads us to the question of the direction that Paint Expo will take after 2022. Do you have any plans up your sleeve that you can reveal to our readers?

Ivonne Simons:

The main priority for us now is to follow up on the existing successes, to make sure that the event is successful for our exhibitors and our visitors and to get everything off to a smooth start in April 2022, particularly in the light of the pandemic.

But there have been some changes in the market that will have an impact and naturally we need to listen to what the industry is saying, to discuss issues and to follow up the ideas that come out of industry meeting places like Paint Expo. It is important for us to develop the exhibition in line with market requirements and in cooperation with our partners.

Markus Geisenberger:

As the new organizer, we need to demonstrate in 2022 that we can continue the success story. That is the main focus of everything we are doing. But we also need to listen carefully and find out where our customers' journey is going. We are not aiming to be smarter ahead of time than the people who have been running Paint Expo for many years, because that would conflict with the goal we have set ourselves. You can work on the assumption that we will have a very ambitious plan for developing Paint Expo in a way that will benefit our customers. In this context, I will mention the fact that at Leipziger Messe we have 25 offices outside Germany. This will allow us to create a quite different impact in the future by ensuring that Paint Expo remains the world's leading trade fair for industrial coating technology and allowing us to invite as many visitors as possible from Germany and from the rest of the world to attend the exhibition.

\section{Will you exploit these in-house synergies this year?}

Markus Geisenberger:

We will, of course, contribute our expertise in this area, but given the tight timeframe and the unusual situation, it is unlikely to have its full impact in 2022 . This is a long-term plan. We want to follow on from the excellent work done in the past and turn Paint Expo into an even higher quality and more international platform over the years to come. //

\section{Thank you for this detailed interview!}

The interviewer was IST editor-in-chief Holger Seybold.

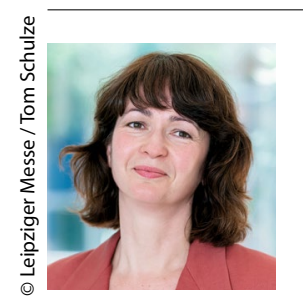

"Our goal is always to provide a better quality service for our customers!"

Ivonne Simons, project director of Paint Expo, Leipziger Messe GmbH (Germany)

\section{Contact}

\section{Leipziger Messe GmbH}

Leipzig (Germany)

Ivonne Simons, project director of Paint Expo

i.simons@leipziger-messe.de

www.leipziger-messe.de

www.paintexpo.de 